\title{
Ependymomas: Prognostic Factors and Outcome Analysis in a Retrospective Series of 33 Patients
}

\author{
Yong-Hyun Chai', Shin Jung ${ }^{1}$, Jung-Kil Lee ${ }^{1}$, In-Young Kim¹, Woo-Youl Jang' ${ }^{1}$, Kyung-Sub Moon¹, \\ Jae-Hyoo Kim ${ }^{1}$, Kyung-Hwa Lee ${ }^{2}$, Seul-Kee Kim³ ${ }^{3}$ Tae-Young Jung ${ }^{1}$ \\ Departments of ${ }^{1}$ Neurosurgery, ${ }^{2}$ Pathology, ${ }^{3}$ Radiology, Chonnam National University Research Institute of Medical Sciences, \\ Chonnam National University Hwasun Hospital \& Medical School, Hwasun, Korea
}

Received July 4, 2017

Revised September 26, 2017

Accepted September 29, 2017

\section{Correspondence}

Tae-Young Jung

Department of Neurosurgery,

Chonnam National University

Hwasun Hospital, 322 Seoyang-ro,

Hwasun-eup, Hwasun 58128, Korea

Tel: $+82-61-379-7666$

Fax: +82-61-379-7673

E-mail: jung-ty@chonnam.ac.kr
Background The purpose of this study was to evaluate the prognostic factors and outcomes in patients with ependymoma to management plans.

Methods Between 1997 and 2013, 33 patients with 25 ependymomas (WHO grade II) and eight anaplastic ependymomas (WHO grade III) were pathologically diagnosed. Six were pediatric patients (mean age, 6.15 years; range, 1.3-11 years), while 27 were adults (mean age, 47.5 years; range, 19-70 years). Of those, there were 12 adult patients with totally resected ependymomas without anaplastic pathology and adjuvant treatment. Prognostic factors were assessed in ependymoma patients. Prognostic factors were studied using Kaplan-Meier estimates in subgroups.

Results For six pediatric patients, the progression-free survival (PFS) was $43.7 \pm 13.5$ months, and the overall survival (OS) was $58.1 \pm 13.7$ months. For 27 adult patients, the PFS was $125.6 \pm 14.3$ months, and the OS was $151.2 \pm 12.5$ months. Age demonstrated a statistically significant effect on PFS ( $p=0.03)$ and OS $(p=0.03)$. In adult ependymomas, the extent of tumor removal significantly affected PFS $(p=0.03)$ and trended towards an effect on OS $(p=0.06)$. Out of 12 patients with totally resected ependymomas without anaplastic pathology and adjuvant treatment, one patient showed tumor recurrence during follow-up (mean, 93.5 months; range, 27.9-162.7 months).

Conclusion Adult patients with ependymomas were found to have better survival rates compared to pediatric patients. We suggest that totally resected adult ependymomas without anaplastic pathology could be observed without any adjuvant treatment, regardless of the tumor location.

Key Words Ependymoma; Surgery; Prognosis; Radiotherapy.

\section{INTRODUCTION}

Intracranial ependymomas are rare glial cell brain tumors, accounting for 3-9\% of all intracranial tumors [1,2]. In patients who have been treated according to best practices, ependymomas are associated with significant mortality. The 10-year survival rate for adult patients is $70-89 \%$ [2-4], and the 10year overall survival rate is $64 \%$ in pediatric patients with ependymomas [5-7].

There have been many reports regarding the treatment re-

This is an Open Access article distributed under the terms of the Creative Commons Attribution Non-Commercial License (http://creativecommons.org/licenses/by-nc/4.0) which permits unrestricted non-commercial use, distribution, and reproduction in any medium, provided the original work is properly cited.

Copyright $\odot 2017$ The Korean Brain Tumor Society, The Korean Society for NeuroOncology, and The Korean Society for Pediatric Neuro-Oncology sults of ependymomas. Although some prognostic factors remain controversial, age, sex, tumor location, pathologic grade, extent of removal, and postoperative adjuvant treatment have all been evaluated as possible prognostic factors $[3,8,9]$. The treatment options for ependymoma are surgery, radiotherapy, and chemotherapy. Age and the extent of surgery were considered as the major predictors of outcome in patients with ependymomas. Adult patients have better prognosis than children. Many studies reported that gross total removal was significantly related to better progression-free survival (PFS) and overall survival (OS) compared to subtotal resection (STR) [2].

Maximal safe resection is the best treatment for ependymoma. Surgery and involved-field radiotherapy remain the standard therapy, especially for posterior fossa ependymomas with or without anaplastic pathology. However, in adult patients, 
postoperative radiotherapy could be considered only for anaplastic ependymomas or suspected residual intracranial tumors, because of better prognosis compared to children. In this study, we focused on the prognosis of totally resected adult ependymomas without anaplastic pathology and postoperative adjuvant treatment. This study could be helpful in selecting the subsequent management of adult ependymomas.

\section{MATERIALS AND METHODS}

\section{Clinical characteristics of patients with ependymomas}

Between 1997 and 2013, 33 patients with ependymomas underwent surgery in the Chonnam National University Hospital and Chonnam National University Hwasun Hospital. A retrospective review of medical records was performed in all patients. This study was approved by our Institutional Review Board (CNUHH-2017-084). Participants in research consented to being involved in this study. Pediatric patients were defined as patients under 18 years old.

Ependymomas were classified as World Health Organization (WHO) grade II ependymomas or grade III anaplastic ependymomas according to the WHO classification system. Data regarding patients' clinical characteristics, such as age, tumor location, extent of removal, pathologic grade, postoperative adjuvant treatment, PFS, and OS, were retrospectively analyzed. Postoperative adjuvant treatment was performed for all WHO grade III ependymoma patients. In WHO grade II ependymoma patients, adjuvant treatment was recommended according to the extent of resection. In adult grade II ependymoma patients with gross total resection (GTR), adjuvant treatment was not recommended. One adult grade III ependymoma patient with STR did not receive adjuvant treatment due to poor general condition. Radiotherapy was performed 4 weeks after the operation for consideration patient's general condition and surgical wound. If the patient's general condition was not good, we considered the patient's condition when determining treatment timing. Conventional external beam radiotherapy was performed in 13 patients. There was no radiation-induced necrosis during follow-up. Adjuvant chemotherapy was performed for a 15-month-old girl.

The high-risk group was defined as patients with WHO grade III tumors or subtotally resected tumors, and the other patients were assigned to the low-risk group. To evaluate efficacy of adjuvant treatment, adult patients were divided into three groups: high risk with adjuvant treatment, high risk without adjuvant treatment, and low risk without adjuvant treatment.

We evaluated the extent of removal by evaluating the intraoperative findings and postoperative contrast-enhanced computer tomography images. The extent of removal was classi- fied as total (100\%) tumor removal, subtotal (over 50\%), or partial (lower than 50\%). Tumor recurrence was based on the presence of a tumor on follow-up magnetic resonance images (MRI) or the development of symptoms. We performed follow-up brain MRI scans every 6 months. We confirmed tumor recurrence by brain MRI. The related symptoms were absent or present depending on the patients. The pattern of recurrence was classified into local, distant, or cerebrospinal fluid (CSF) dissemination. Local recurrence was defined as a recurrence at the primary tumor site, and distant recurrence was defined as spatially separated recurrence within the brain. CSF dissemination was defined as a recurrence in the ventricles, subarachnoid space, and spine.

\section{Pediatric ependymomas}

Table 1 summarizes the patients' information. Of the six pediatric patients with ependymomas receiving treatment, one patient $(16.6 \%)$ had a supratentorial tumor, and five patients (83.3\%) had infratentorial tumors. Three patients (50.0\%) had grade II ependymomas, and three patients (50.0\%) had grade III. GTR was performed in two patients (33.3\%) and STR in four $(66.6 \%)$. Post-operative adjuvant therapy was administered to five patients. Radiation treatment was administered to four patients (66.6\%), and one patient was treated with chemotherapy $(16.6 \%)$. In the radiation treatment, three patients received only local brain radiation therapy consisting of 4,000, 4,500, and 5,400 cGy, respectively. One patient received local and craniospinal irradiation (CSI) during the same period. The radiation dose was 3,820 cGy in the local brain and 1,700 cGy in the CSI. Chemotherapy with vincristine, prednisolone, and carmustine was administered to one patient according to the CCG-9445 protocol of the Children's Cancer Group highgrade glioma study for 5 months. The mean follow-up duration was 48.5 months (range, 16.9-102.8 months). Tumor recurrence occurred in three patients (50\%). Two patients showed local recurrence on follow-up at 32.1 months and 72.0 months, respectively. One patient showed local recurrence and CSF dissemination at 8.8 months.

\section{Adult ependymomas}

A total of 27 adult patients with ependymoma were treated; 22 patients (81.4\%) had WHO grade II ependymomas, and five (18.5\%) had WHO grade III ependymomas. One patient with WHO grade II ependymoma demonstrated malignant transformation into WHO grade III ependymoma after recurrence. The tumor was located supratentorially in seven patients (25.9\%), infratentorially in 13 (48.1\%), and in the spinal cord in seven (25.9\%). The tumor was totally resected in 15 patients (55.5\%), and an STR was performed in 12 (44.4\%). Postoperative adjuvant radiation therapy was administered to nine pa- 
Table 1. Summary of characteristics for all patients

\begin{tabular}{|c|c|c|c|c|c|c|c|}
\hline Number & Age (years) & Sex & WHO grade & Locations & Extent of removal & $\begin{array}{l}\text { Postoperative } \\
\text { adjuvant Tx }\end{array}$ & Outcome \\
\hline \multicolumn{8}{|c|}{ Pediatric patients $(n=6)$} \\
\hline 1 & 1.3 & $\mathrm{~F}$ & III & Supratentorial & STR & Chemotherapy & Death \\
\hline 2 & 3 & $\mathrm{~F}$ & II & Infratentorial & GTR & None & Relapse \\
\hline 3 & 5 & M & II & Infratentorial & GTR & Local RT & Relapse \\
\hline 4 & 4 & $\mathrm{~F}$ & III & Infratentorial & STR & CSI & Death \\
\hline 5 & 3 & M & III & Infratentorial & STR & Local RT & Survived \\
\hline 6 & 11 & $\mathrm{~F}$ & III & Infratentorial & STR & Local RT & Relapse \\
\hline \multicolumn{8}{|c|}{ Adult patients $(\mathrm{n}=27)$} \\
\hline 1 & 60 & $\mathrm{~F}$ & II & Supratentorial & GTR & None & Survived \\
\hline 2 & 55 & M & II & Supratentorial & GTR & None & Survived \\
\hline 3 & 23 & M & II & Supratentorial & STR & None & Survived \\
\hline 4 & 19 & M & II & Supratentorial & STR & Local RT & Survived \\
\hline 5 & 39 & $\mathrm{~F}$ & III & Supratentorial & STR & None & Relapse \\
\hline 6 & 44 & M & III & Supratentorial & GTR & Local RT & Survived \\
\hline 7 & 27 & M & III & Supratentorial & STR & Local RT & Relapse \\
\hline 8 & 68 & $\mathrm{~F}$ & II & Infratentorial & GTR & None & Survived \\
\hline 9 & 36 & $\mathrm{~F}$ & II & Infratentorial & GTR & None & Relapse \\
\hline 10 & 20 & M & II & Infratentorial & GTR & None & Survived \\
\hline 11 & 21 & $\mathrm{~F}$ & II & Infratentorial & GTR & None & Survived \\
\hline 12 & 41 & $\mathrm{~F}$ & II & Infratentorial & STR & None & Survived \\
\hline 13 & 54 & M & II & Infratentorial & STR & None & Relapse \\
\hline 14 & 36 & $\mathrm{~F}$ & II & Infratentorial & STR & None & Survived \\
\hline 15 & 34 & M & II & Infratentorial & STR & Local RT & Survived \\
\hline 16 & 55 & $\mathrm{~F}$ & II & Infratentorial & STR & Local RT & Relapse \\
\hline 17 & 32 & M & II & Infratentorial & STR & Local RT & Survived \\
\hline 18 & 30 & $\mathrm{~F}$ & III & Infratentorial & GTR & Local RT & Survived \\
\hline 19 & 32 & M & III & Infratentorial & GTR & CSI & Survived \\
\hline 20 & 29 & $\mathrm{~F}$ & III & Infratentorial & STR & Local RT & Relapse \\
\hline 21 & 43 & $\mathrm{~F}$ & II & Spinal cord & GTR & None & Survived \\
\hline 22 & 65 & $\mathrm{~F}$ & II & Spinal cord & GTR & None & Survived \\
\hline 23 & 65 & M & II & Spinal cord & GTR & None & Relapse \\
\hline 24 & 52 & $\mathrm{~F}$ & II & Spinal cord & GTR & None & Survived \\
\hline 25 & 57 & M & II & Spinal cord & GTR & None & Survived \\
\hline 26 & 64 & $\mathrm{~F}$ & II & Spinal cord & GTR & None & Death \\
\hline 27 & 70 & M & II & Spinal cord & STR & None & Survived \\
\hline
\end{tabular}

M, male; F, female; WHO, World Health Organization; GTR, gross total removal; STR, subtotal removal; Tx, treatment; WBRT, whole brain radiotherapy; RT, radiotherapy; CSI, craniospinal irradiation

tients (33.3\%). Eight patients received 4,500 cGy to 5,400 cGy local brain radiotherapy and one patient received $3,240 \mathrm{cGy}$ CSI. The mean follow-up duration was 83.8 months (range, 3.8-182.2 months). Tumor recurrence occurred in seven patients $(25.9 \%)$. Mean recurrence period of relapsed patients was 12.0 months (range, 1.6-46.6 months). Five patients developed local recurrence, and two patients developed local recurrence combined with CSF dissemination. Table 2 summarizes the information of relapsed adult patients.

\section{Statistical analysis}

We defined the mean range according to the follow-up duration and determined single-variable effects on PFS and OS via univariate analyses. The single variables were age, sex, tumor location, extent of removal, pathology, and adjuvant therapy. PFS was calculated from the dates of surgery to radiological progression or the last follow-up visit, and OS was calculated from the dates of surgery to death or final follow-up. Survival probability was calculated using the Kaplan-Meier method by performing comparisons with the log-rank test. All statistical 
Table 2. Summary of characteristics for seven adult patients with recurrence

\begin{tabular}{cccccccccc}
\hline Number & $\begin{array}{c}\text { Age } \\
\text { (years) }\end{array}$ & Sex & $\begin{array}{c}\text { WHO } \\
\text { grade }\end{array}$ & Location & $\begin{array}{c}\text { Extent of } \\
\text { removal }\end{array}$ & Adjuvant Tx & $\begin{array}{c}\text { PFS } \\
\text { (months) }\end{array}$ & $\begin{array}{c}\text { OS } \\
\text { (months) }\end{array}$ & Outcome \\
\hline 5 & 39 & F & III & Supratentorial & STR & None & 1.6 & 5.2 & Death \\
7 & 27 & M & III & Supratentorial & STR & Local RT & 15.4 & 24.3 & Death \\
9 & 36 & F & II & Infratentorial & GTR & None & 9.2 & 90.6 & Alive \\
13 & 54 & M & II & Infratentorial & STR & None & 12.0 & 32.6 & Alive \\
16 & 55 & F & II & Infratentorial & STR & Local RT & 3.9 & 3.9 & Death \\
20 & 29 & F & III & Infratentorial & STR & Local RT & 13.4 & 13.4 & Death \\
23 & 65 & M & II & Spinal cord & GTR & None & 46.6 & 46.6 & Death \\
\hline
\end{tabular}

M, male; F, female; WHO, World Health Organization; GTR, gross total removal; STR, subtotal removal; Tx, treatment; RT, radiotherapy; PFS, progression-free survival; OS, overall survival
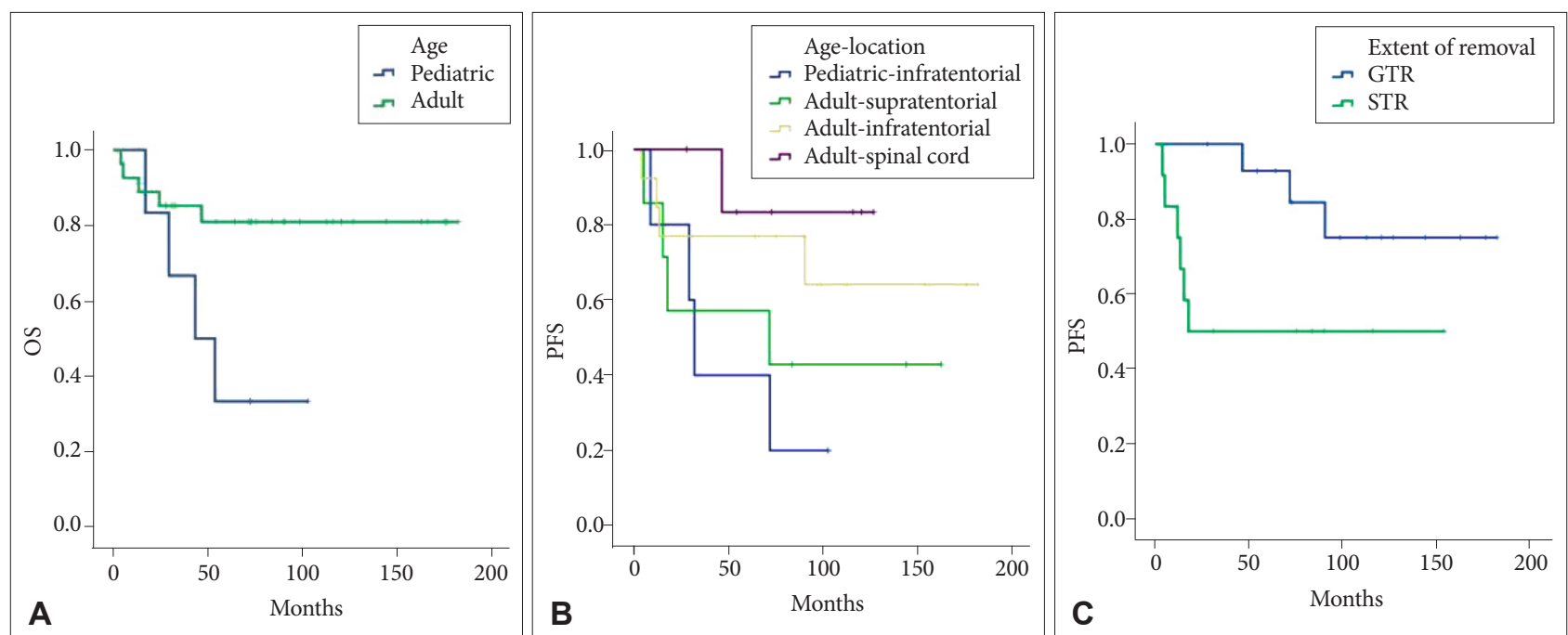

Fig. 1. Kaplan-Meier curves for PFS and OS. A: OS depends on age in all patients. The three-year OS rate was $80.9 \%$ for adults, and $66.7 \%$ for pediatric patients $(p=0.03)$. B: PFS depends on age and tumor location in all patients. Pediatric-infratentorial group showed the trend of poor prognosis compared to adult-spinal cord group in terms of PFS. The three-year PFS rate was $40.0 \%$ for pediatric-infratentorial group, and $100 \%$ for adult-spinal cord group $(p=0.03)$. C: PFS with extent of removal in adult patients. The one-year PFS rate was $100 \%$ for GTR, and $75 \%$ for STR ( $p=0.04)$. PFS, progression-free survival; OS, overall survival; GTR, gross total resection; STR, subtotal resection.

analyses were performed with a significance level of $p<0.05$ using SPSS 21.0 (IBM Corp., Armonk, NY, USA).

\section{RESULTS}

\section{Progression-free survival and overall survival of all ependymomas}

Six patients were pediatric patients (mean age, 6.15 years; range, 1.3-11.0 years) with a male-to-female ratio of 2:4, and 27 were adults (mean age, 47.5 years; range, 19.0-70.0 years) with a male-to-female ratio of 13:14. The mean follow-up duration was 66.7 months (range, 3.9-144.1 months). In all patients, the mean PFS was $114.0 \pm 13.8$ months and mean OS was 138.0 \pm 12.6 months. There was no statistical significance in the relationship between PFS and sex, tumor location, or pathology. Adult patients were found to be associated with a longer PFS $(p=0.03)$ and OS ( $p=0.03)$ (Fig. 1A). Six pediatric patients had a mean PFS of $43.7 \pm 13.5$ months and a mean OS of $58.1 \pm 13.7$ months, while 27 adults had a mean PFS of $127.8 \pm 14.8$ months and a mean OS of $151.2 \pm 12.5$ months. Depending on the age and location, we divided the patients into four groups: pediatric-infratentorial, adult-supratentorial, adult-infratentorial, and adult-spinal cord. Pediatric-infratentorial group showed a trend of poor prognosis compared to adult-spinal cord group in terms of PFS ( $p=0.032$ ) (Fig. 1B). PFS was $49.0 \pm 15.1$ months in pediatric-infratentorial group, $85.5 \pm 26.3$ months in adultsupratentorial group, $130.7 \pm 21.3$ months in adult-infratentorial group, and $113.5 \pm 12.2$ months in adult-spinal cord group.

Pediatric-infratentroial group was not statistical poor significance for OS compared adult-group ( $p=0.358)$. OS was $66.4 \pm 13.7$ months in pediatric-infratentorial group, $129.3 \pm 27.4$ months in adult-supratentorial group, $155.5 \pm 17.4$ months in adult-infratentorial group, and $113.5 \pm 12.2$ months in adultspinal cord group. There was no statistically significant rela- 
tionship with sex, tumor location, extent of removal, or pathology. However, there was a statistically significant relationship with age.

\section{Progression-free survival and overall survival of 27 adults ependymomas}

These data were summarized in Table 3. Adult ependymomas were analyzed for clinical prognostic factors. For PFS, there was no statistically significant relationship with sex $(p=0.64)$, tumor location ( $p=0.28$ ), pathology ( $p=0.23$ ), or postoperative adjuvant treatment $(p=0.13)$. However, the extent of removal had a significant effect on PFS ( $p=0.04$ ) (Fig. 1C); the mean PFS was $154.6 \pm 14.0$ months for GTR, and 82.7 \pm 20.6 months for STR. The one-year PFS rate was $100 \%$ for GTR, and $75 \%$ for STR. For OS, there was no significant effect of $\operatorname{sex}(p=0.63)$, tumor location ( $p=0.78$ ), pathology $(p=0.20)$, or postoperative adjuvant treatment $(p=0.31)$. A trend towards a better OS was found in patients who was underwent GTR $(p=0.06)$; the mean OS was $172.5 \pm 9.3$ months for GTR and $120.6 \pm 22.3$ months for STR.

\section{The prognosis of adult patients, especially focused on twelve totally resected ependymomas without anaplastic pathology and postoperative adjuvant treatment}

Twelve adult patients underwent total resection of the ependymoma without anaplastic pathology and adjuvant treatment. The mean age of the patients was 54.3 years (range, 20.068.07 years). The male-to-female ratio was 4:8. The tumor was located supratentorially in two patients (16.6\%), infratentorially in four (33.3\%), and in the spinal cord in six (50\%). The mean follow-up duration was 93.5 months (range, 27.9-162.7 months). One out of the 12 patients developed local recurrence at the primary origin site.

The clinical course of the one case of recurrence is described (Fig. 2). A 36-year-old woman had a 3.7-cm-sized ependymoma in the fourth ventricle that was totally resected via a telovelar approach. One year later, follow-up MRI showed a $1-\mathrm{cm}$-sized recurrent lesion associated with enhancement of the fourth ventricle. Local brain radiotherapy (5,400 cGy) and spinal irradiation (2,160 cGy) were performed. Over the course of 92 months of follow-up after radiotherapy, no recurrence was seen.

\section{DISCUSSION}

Many reports have published potential prognostic factors for mortality in patients with ependymoma to help plan treatments $[1,5,10]$. Although the results have been controversial, prognostic factors such as age, sex, tumor location, tumor grade, extent of removal, and adjuvant treatment have been evaluated in several studies $[1,3,8]$. Age and extent of resection can be considered as the major predictors of outcome.

Tumor location was important factor in some studies. Infratentorial ependymoma was a poorer prognostic factor than supratentorial ependymoma [5]. But some authors maintain that outcome is worse with supratentorial tumor than infratentorial tumor $[4,8]$. In our study, pediatric infratentorial epen-

Table 3. Outcomes of adult ependymomas $(n=27)$

\begin{tabular}{|c|c|c|c|c|}
\hline Prognostic factors & PFS (months) & OS (months) & PFS ( $p$ value) & OS ( $p$ value $)$ \\
\hline Sex & & & 0.64 & 0.63 \\
\hline Male $(n=13)$ & $117.7 \pm 20.4$ & $152.6 \pm 15.3$ & & \\
\hline Female $(n=14)$ & $134.5 \pm 20.1$ & $144.8 \pm 19.2$ & & \\
\hline Tumor location & & & 0.28 & 0.78 \\
\hline Supratentorial $(\mathrm{n}=7)$ & $85.4 \pm 26.3$ & $129.3 \pm 27.4$ & & \\
\hline Infratentorial $(\mathrm{n}=13)$ & $130.6 \pm 21.2$ & $155.5 \pm 17.4$ & & \\
\hline Spinal cord $(n=7)$ & $113.5 \pm 12.2$ & $113.5 \pm 12.2$ & & \\
\hline Extent of removal & & & 0.04 & 0.06 \\
\hline Total resected $(\mathrm{n}=15)$ & $154.6 \pm 14.0$ & $172.5 \pm 9.3$ & & \\
\hline Subtotal resected $(\mathrm{n}=12)$ & $82.7 \pm 20.6$ & $120.6 \pm 22.3$ & & \\
\hline Pathology & & & 0.23 & 0.20 \\
\hline WHO grade II $(n=21)$ & $122.8 \pm 13.8$ & $152.7 \pm 12.0$ & & \\
\hline WHO grade III $(n=6)$ & $93.0 \pm 33.9$ & $116.9 \pm 35.8$ & & \\
\hline Postoperative adjuvant treatment & & & 0.13 & 0.31 \\
\hline High risk with adjuvant $T x(n=9)$ & $91.5 \pm 27.0$ & $126.1 \pm 26.5$ & & \\
\hline High risk without $\operatorname{Tx}(\mathrm{n}=6)$ & $105.6 \pm 28.0$ & $139.4 \pm 24.5$ & & \\
\hline Low risk without $\mathrm{Tx}(\mathrm{n}=12)$ & $151.2 \pm 12.5$ & $152.1 \pm 10.1$ & & \\
\hline
\end{tabular}

Tx, treatment; PFS, progression-free survival; OS, overall survival; WHO, World Health Organization 

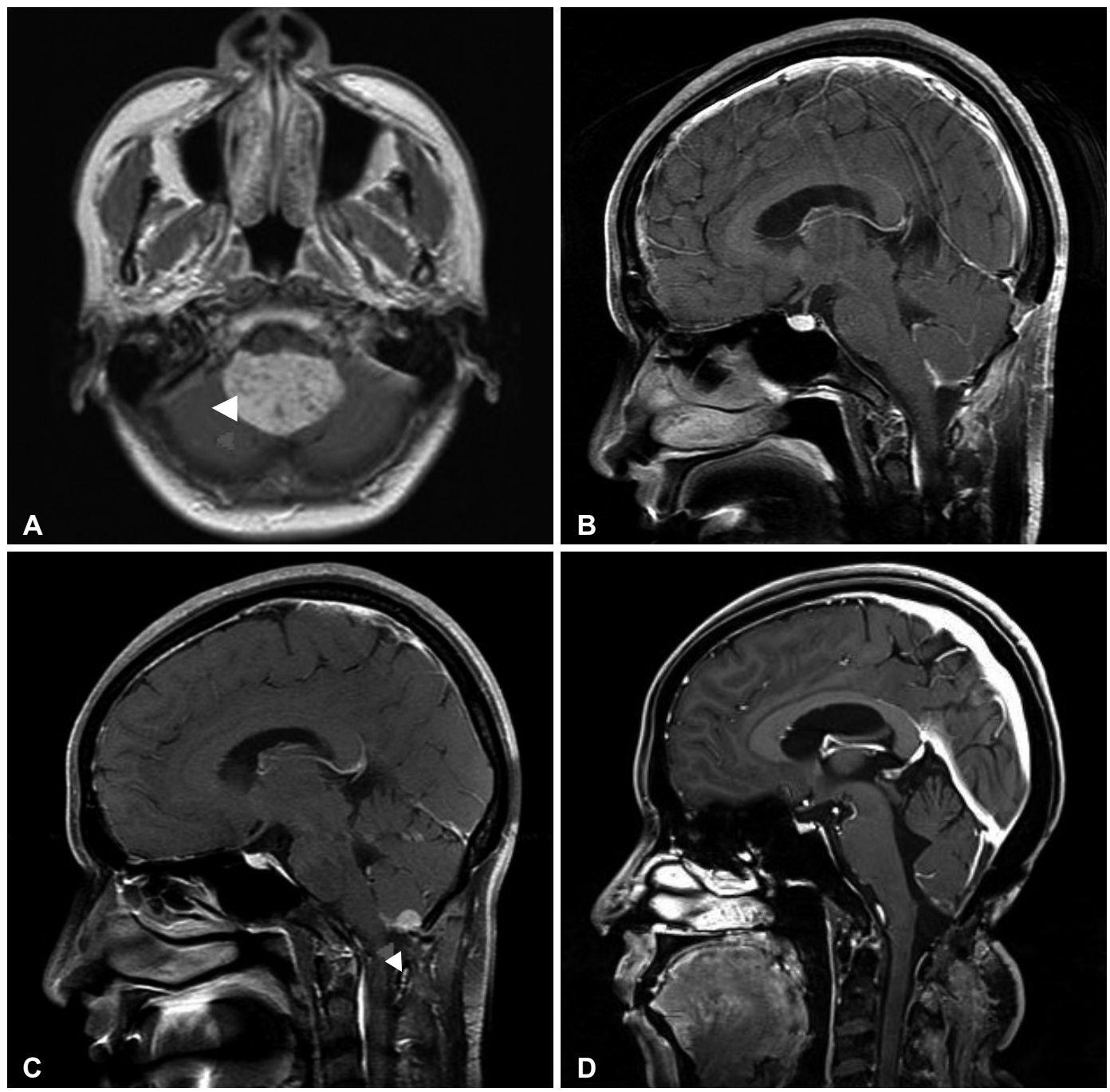

Fig. 2. One case of recurrence out of 12 adult patients with totally resected ependymomas without anaplastic pathology or postoperative adjuvant treatment. A: A 3.7-cm-sized ependymoma in the fourth ventricle (white arrowhead). B: No remnants of the lesion after total resection. C: On first year after surgery, a 1-cm-sized recurrent lesion (white arrowhead). D: No recurrence over the course of 92 months of follow-up.

dymomas showed a poorer prognosis when compared to adult ependymomas. Location could affect the prognosis differently depending on the patient's age.

Young age is a major cause of poor outcome [11,12]. Patients in whom ependymomas are detected at an early age are extensively reported as having a very poor prognosis. Some reports have suggested that the incidence of high-grade tumors tended to be higher in younger patients and pediatric ependymomas were more usually located in the posterior fossa as compared with adult ependymomas. Children aged less than one year were reported to have a 5-year OS of $42.4 \%$ [10]. The 5 -year OS improved with increasing age to reach $74.7 \%$ in patients aged between 5 and 9 years and $81.4 \%$ in patients aged between 10 and 14 years [4].

As other prognostic factors, the tumor location and histologic grade could be important; however, they remain contro- versial. Infratentorially located tumors are associated with poorer survival rates than those located supratentorially [5]. Several studies suggested an obvious decline in survival for patients with WHO grade III ependymomas when compared with those with grade II tumors [13]. In this study, there was neither a correlation between location and prognosis nor histologic grade. Recently, a molecular grouping study of ependymomas showed that there is a correlation between two of these groups, ST-EPN-RELA and PF-EPN-A, and a poor prognosis [14]. In the future, genetic characteristics could be considered when formulating the treatment plan with the above clinical prognostic factors.

Surgery is the standard treatment for ependymomas. The extent of resection is a reliable prognostic factor that has been previously reported $[1,2,15]$. These reports emphasize that the maximal safe resection should be performed in patients with 
ependymomas. One clinical trial showed that GTR was an independent risk factor regardless of the pathologic grade [16]. Maximal surgical resection should be carried out, if possible. The development of surgical techniques and instruments, such as neuronavigation or intraoperative monitoring, could improve the rate of resection and decrease complications. In pediatric ependymomas, GTR with adjuvant local radiotherapy has been established as the standard treatment, especially for tumors located in the posterior fossa $[4,17]$.

Radiotherapy is an important treatment modality due to the radiosensitivity of ependymomas. CSI has also been accepted in cases of leptomeningeal dissemination. For adult patients, the radiotherapy has postoperatively been performed, regardless of the histologic grade of the tumor and the extent of removal. However, recent studies have suggested that adult patients with WHO grade II ependymoma who received GTR did not immediately need radiotherapy if tumor spreading was not seen in the CSF $[18,19]$. The optimal management of adult ependymomas remains still controversial.

In this study, postoperative treatment was performed in adult patients with poor prognostic factors, such as subtotal resected or grade III tumor. We divided adult patients into three groups for evaluation of prognosis. Even if there was no statistical significance, the high-risk group with adjuvant treatment showed the poorer prognosis compared to the low-risk group.

In our study, only one out of the 12 patients who had totally resected ependymomas without anaplastic pathology developed local recurrence. Although recurrence occurred, there was no subsequent recurrence after additional radiotherapy. This suggests that additional treatment could be needed when recurrence is observed after radiological follow-up. A "wait and see" policy could be recommended in totally resected WHO grade II adult ependymomas, regardless of the tumor location. On the contrary, the prognosis of pediatric ependymoma is different, and pediatric patients had a poorer prognosis than adult patients. Similar to previous reports, we also do not recommend a "wait and see" policy especially for infratentorial pediatric ependymoma.

There were some limitations of this study. The main limitation of this study is its retrospective nature and relatively small patient population, which undoubtedly limited the statistical power of some of our analyses. Additionally, we did not perform a genetic study.

In conclusion, we analyzed 33 ependymoma patients for prognostic factors. Age is an important factor of prognosis. In adult patients, totally resected adult ependymomas without anaplastic pathology could be monitored without any adjuvant treatment, regardless of the tumor location. This study could be helpful in developing the subsequent management plan when treating adult ependymomas.

\section{Conflicts of Interest}

The authors have no financial conflicts of interest.

\section{REFERENCES}

1. Oya N, Shibamoto Y, Nagata Y, Negoro Y, Hiraoka M. Postoperative radiotherapy for intracranial ependymoma: analysis of prognostic factors and patterns of failure. J Neurooncol 2002;56:87-94.

2. Metellus P, Barrie M, Figarella-Branger D, et al. Multicentric French study on adult intracranial ependymomas: prognostic factors analysis and therapeutic considerations from a cohort of 152 patients. Brain 2007; 130(Pt 5):1338-49.

3. Paulino AC, Wen BC, Buatti JM, et al. Intracranial ependymomas: an analysis of prognostic factors and patterns of failure. Am J Clin Oncol 2002;25:117-22.

4. Mansur DB, Perry A, Rajaram V, et al. Postoperative radiation therapy for grade II and III intracranial ependymoma. Int J Radiat Oncol Biol Phys 2005;61:387-91.

5. Tamburrini G, D’Ercole M, Pettorini BL, Caldarelli M, Massimi L, Di Rocco C. Survival following treatment for intracranial ependymoma: a review. Childs Nerv Syst 2009;25:1303-12.

6. Shu HK, Sall WF, Maity A, et al. Childhood intracranial ependymoma: twenty-year experience from a single institution. Cancer 2007;110:43241.

7. van Veelen-Vincent ML, Pierre-Kahn A, Kalifa C, et al. Ependymoma in childhood: prognostic factors, extent of surgery, and adjuvant therapy. J Neurosurg 2002;97:827-35.

8. Metellus P, Figarella-Branger D, Guyotat J, et al. Supratentorial ependymomas: prognostic factors and outcome analysis in a retrospective series of 46 adult patients. Cancer 2008;113:175-85.

9. Merchant TE, Li C, Xiong X, Kun LE, Boop FA, Sanford RA. Conformal radiotherapy after surgery for paediatric ependymoma: a prospective study. Lancet Oncol 2009;10:258-66.

10. Gatta G, Botta L, Rossi S, et al. Childhood cancer survival in Europe 1999-2007: results of EUROCARE-5--a population-based study. Lancet Oncol 2014;15:35-47.

11. McGuire CS, Sainani KL, Fisher PG. Both location and age predict survival in ependymoma: a SEER study. Pediatr Blood Cancer 2009; 52:65-9.

12. Ward S, Harding B, Wilkins P, et al. Gain of 1q and loss of 22 are the most common changes detected by comparative genomic hybridisation in paediatric ependymoma. Genes Chromosomes Cancer 2001;32:5966.

13. Kurt E, Zheng PP, Hop WC, et al. Identification of relevant prognostic histopathologic features in 69 intracranial ependymomas, excluding myxopapillary ependymomas and subependymomas. Cancer 2006; 106:388-95.

14. Pajtler KW, Witt H, Sill M, et al. Molecular classification of ependymal tumors across all CNS compartments, histopathological grades, and age groups. Cancer Cell 2015;27:728-43.

15. Korshunov A, Neben K, Wrobel G, et al. Gene expression patterns in ependymomas correlate with tumor location, grade, and patient age. Am J Pathol 2003;163:1721-7.

16. Gajjar A, Packer RJ, Foreman NK, et al. Children's Oncology Group's 2013 blueprint for research: central nervous system tumors. Pediatr Blood Cancer 2013;60:1022-6.

17. Paulino AC. Radiotherapeutic management of intracranial ependymoma. Pediatr Hematol Oncol 2002;19:295-308.

18. Timmermann B, Kortmann RD, Kühl J, et al. Combined postoperative irradiation and chemotherapy for anaplastic ependymomas in childhood: results of the German prospective trials HIT 88/89 and HIT 91. Int J Radiat Oncol Biol Phys 2000;46:287-95.

19. Metellus P, Guyotat J, Chinot O, et al. Adult intracranial WHO grade II ependymomas: long-term outcome and prognostic factor analysis in a series of 114 patients. Neuro Oncol 2010;12:976-84. 